\title{
Bedside rapid placement of nasointestinal feeding tube via ultrasound-guided stylet positioning in critical COVID-19 patients
}

\author{
Chuan-xi Chen, Zheng-deng Wei, Yong-jun Liu, Shou-zhen Cheng and Xiang-dong Guan * (DD
}

\section{Dear Editor,}

During our clinical work treating the breakout of coronavirus disease 2019 (COVID-19) in Wuhan, China. Good supportive care, including nutritional therapy, remains fundamental in managing critically ill patients with COVID-19, initiating enteral nutrition (EN) within the first 24-48 h after intensive care unit (ICU) admission in patients who are unable to eat unless contraindications exist [1]. Further, for those patients who were receiving mechanical ventilation or even in prone position, administration of analgosedation is known to slow down gastric emptying and thus post-pyloric feeding should be considered in case of persisting gastric retention [2,3]. Due to the highly contagious nature of COVID-19, the implementation of heavy personal protective equipment (PPE) significantly increased the difficulties of performing clinical procedures, such as placing a bedside nasointestinal feeding tube without normal methods like auscultation with insufflation of air. To promptly and precisely finish the procedure with minimal exposure, we introduced the use of ultrasound-guided nasointestinal feeding tube positioning in those serious and critical patients [4].

In this report, we summarized our experience using ultrasound guidance for bedside nasointestinal feeding tube placement to significantly enhance the success rate while reducing time and labor.

We used a $140-\mathrm{cm}$-long nasointestinal tube with a stylet (20-9551, 10FR mm, CORPAK MedSystems Inc. IL, USA) and TE7 point of care ultrasound

\footnotetext{
* Correspondence: guanxiangdong1962@163.com Department of Critical Care Medicine, The First Affiliated Hospital, Sun Yat-Sen University, Guangzhou 510080, China
}

system (Mindray, Shenzhen, China). Ten minutes prior to the procedure, the patient was given metoclopramide $10 \mathrm{mg}$ IV. Then, the tube was inserted intranasally for approximately $30-40 \mathrm{~cm}$, and a linear transducer was placed on the neck to probe the tube image in the esophagus (Fig. 1a), to avoid misplacement into the trachea. After esophageal placement was confirmed, we advanced the tube to $50-60 \mathrm{~cm}$ into the stomach. Then, the patient was placed in a $45^{\circ}$ right dorsal position; simultaneously, a convex transducer was used to position the antral sinus region. A quick shot of $10-20 \mathrm{ml}$ normal saline was given to assure that the tube wall and stylet could be detected under scan. Tube entry was confirmed as observing the tram-track sign with stylet between the walls in the longitudinal section (Fig. 1b), and then tube was slowly pushed subsequently. Since using ultrasound is difficult to probe jejunal content, we introduced the "stylet withdraw and contrast" sign to position the tube, when the tube was inserted about $80-100 \mathrm{~cm}$; the stylet was slowly withdrawn until the tip was detected in pylorus (Fig. 1c); and the length the stylet exposed at tail of the tube represented depth of the tip of tube beyond the pylorus. The normal length of duodenum is about $20-25 \mathrm{~cm}$; therefore, when the stylet tip reached $20-25 \mathrm{~cm}$ postpyloricly, it was considered as jejunal entry. And the procedure was concluded. Subsequently, the tip position was further confirmed by bedside abdominal radiology (Fig. 1d).

Three patients received this ultrasound-guided nasointestinal feeding tube placement uneventfully in one attempt; the median time of procedure was 18 (15-25) min, which reduced procedural time and patients' suffering and most importantly, minimized 


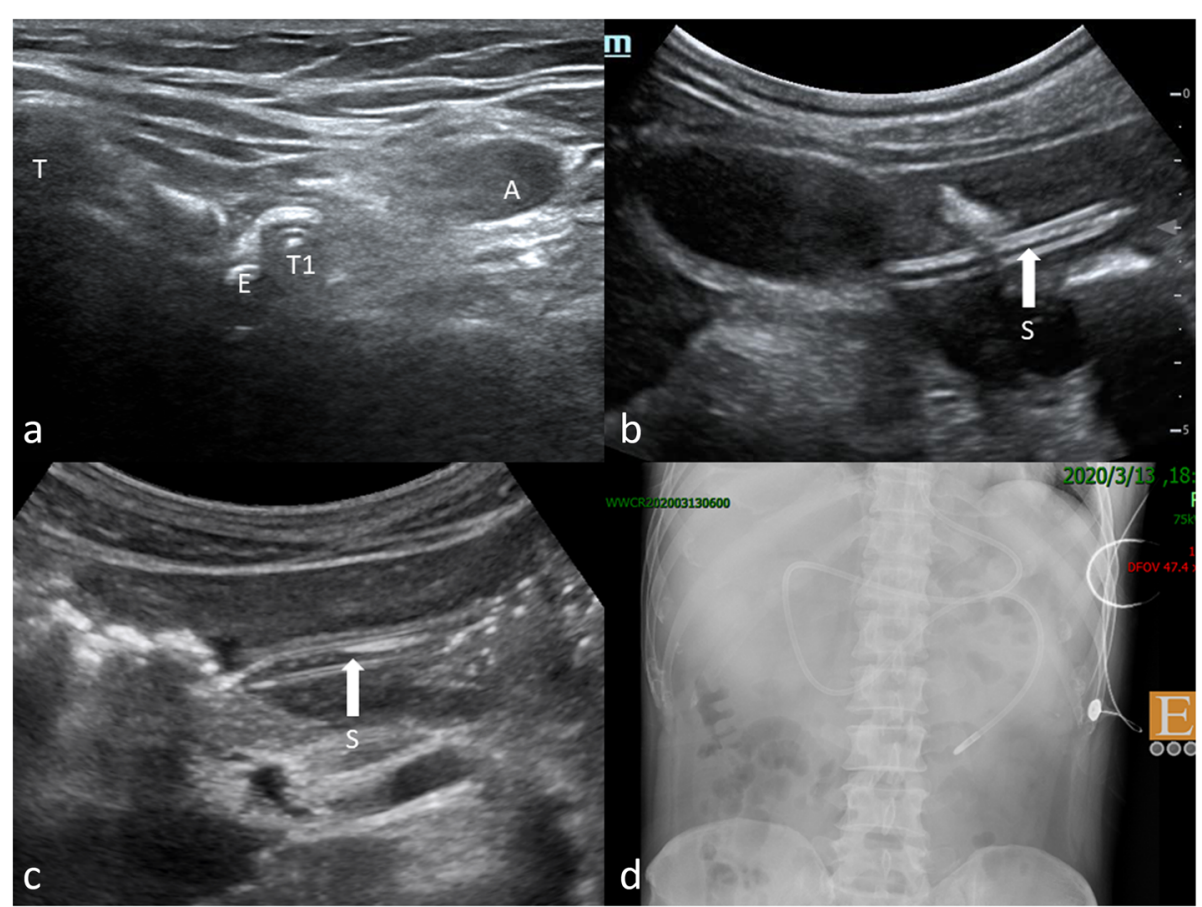

Fig. 1 The location of the trachea (T), carotid artery (A), nasointestinal tube (T1), and esophagus (E) (a). Tram-track signs with stylet (S) in the longitudinal section (b). The stylet (S) tip in pylorus in the longitudinal section (c). Abdominal plain radiograph showed the tip of the tube (d)

the exposure of medical staff in the high-virulent environment. Furthermore, the ultrasound-guided stylet method precisely helped us to confirm the tip position reaching the jejunum rather than the tube bending in stomach and maximally decreases aspiration risk, the accuracy of this novel method needs be tested on more cases. We propose to introduce this novel procedure to care for critical COVID-19 patients and protect medical staff.

\section{Acknowledgements}

Not applicable.

\section{Authors' contributions}

Chuan-xi Chen contributed to the original draft. Xiang-dong Guan contributed to the supervision. The authors read and approved the final manuscript.

\section{Funding}

This work was supported by Sun Yat-sen University Clinical Research Program 5010 (No. 2007015).

Availability of data and materials

The data are available from the corresponding author.

Ethics approval and consent to participate

Not applicable.

\section{Consent for publication}

Not applicable.

\section{Competing interests}

The authors declare that there are no conflicts of interest.
Received: 23 April 2020 Accepted: 12 May 2020

Published online: 18 June 2020

\section{References}

1. Singer $P$, Blaser AR, Berger MM, Alhazzani W, Calder PC, Casaer MP, Hiesmayr M, Mayer K, Montejo JC, Pichard C, et al. ESPEN guideline on clinical nutrition in the intensive care unit. Clin Nutr. 2019;38(1):48-79.

2. Reintam Blaser A, Starkopf J, Alhazzani W, Berger MM, Casaer MP, Deane AM, Fruhwald S, Hiesmayr M, Ichai C, Jakob SM, et al. Early enteral nutrition in critically ill patients: ESICM clinical practice guidelines. Intensive Care Med. 2017:43(3):380-98.

3. Yuan ST, Zhang WH, Zou L, Sun JK, Liu Y, Shi QK. Practice of novel method of bedside postpyloric tube placement in patients with coronavirus disease 2019. Crit Care. 2020;24(1):135.

4. Zhang Q, Sun JH, Liu JT, Wang XT, Liu DW. Placement of a jejunal feeding tube via an ultrasound-guided antral progressive water injection method. Chin Med J. 2018;131(14):1680-5.

\section{Publisher's Note}

Springer Nature remains neutral with regard to jurisdictional claims in published maps and institutional affiliations.

Ready to submit your research? Choose BMC and benefit from:

- fast, convenient online submission

- thorough peer review by experienced researchers in your field

- rapid publication on acceptance

- support for research data, including large and complex data types

- gold Open Access which fosters wider collaboration and increased citations

- maximum visibility for your research: over $100 \mathrm{M}$ website views per year

At BMC, research is always in progress.

Learn more biomedcentral.com/submissions 